\title{
Gerakan Siaga Masyarakat Anti-Diabetes Mellitus (SIMANIS) Melalui Kartu SIDIA (Skrining Pre-Diabetes) di Kabupaten Semarang \\ Anti-Diabetes Mellitus Community Alert Movement (SIMANIS) Through SIDIA Card (Pre- Diabetes Screening) in Semarang Regency
}

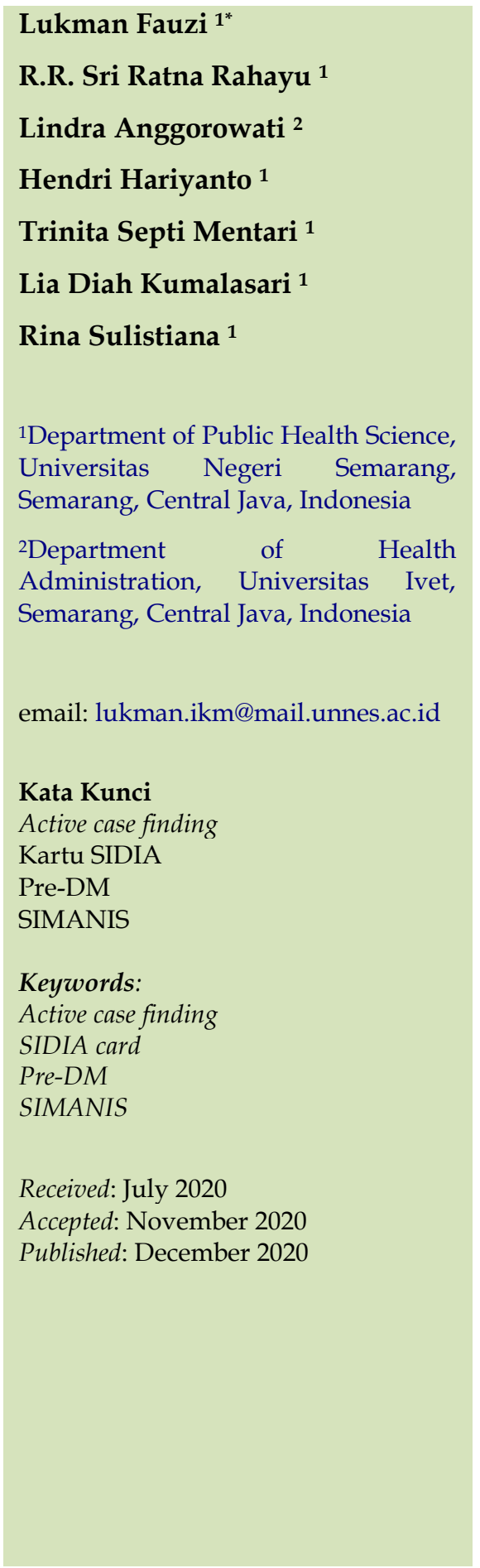

\begin{abstract}
Abstrak
Diabetes Mellitus (DM) merupakan salah satu penyakit tidak menular yang memberi andil dalam penyebab kematian. Berdasarkan analisis situasi di Desa Kawengen, Kabupaten Semarang diperoleh beberapa permasalahan terkait kejadian DM, termasuk Program Pos Pembinaan Terpadu Penyakit Tidak Menular (Posbindu PTM) yang tidak berjalan optimal. Berdasarkan permasalahan tersebut, perlu dibentuk sebuah gerakan yang diberi nama Gerakan Siaga Masyarakat Anti-Diabetes Mellitus (SIMANIS). Deteksi dan penemuan kasus pre-DM secara aktif (active case finding) bertujuan untuk menjaring masyarakat yang sudah memiliki gejala pre-DM, namun dirinya tidak mengetahui. Selanjutnya, apabila terjaring dapat di follow up agar bersedia memeriksakan diri ke unit pelayanan kesehatan sebelum terjadi penyulit. Pelaksanaan kegiatan pengabdian kepada masyarakat ini dilakukan dengan empat tahap, yaitu pembentukan Kader SIMANIS, edukasi pencegahan dan pengendalian DM kepada kader SIMANIS dan masyarakat, ToT cara pengisian dan penggunaan Kartu SIDIA (skrining pre-Diabetes) kepada Kader SIMANIS, dan penggunaan Kartu SIDIA untuk deteksi dini/active case finding pre-DM. Terdapat peningkatan skor pengetahuan pre-post edukasi dari 7,59+1,5 menjadi 8,93+0,9 dan peningkatan skor sikap prepost edukasi dari $7,96+1,22$ menjadi 9,07+0,78. SIMANIS melalui penggunaan Kartu SIDIA dapat digunakan sebagai upaya peningkatan kesadaran masyarakat dalam pencegahan, deteksi dini, dan penemuan kasus DM.
\end{abstract}

\begin{abstract}
Diabetes Mellitus (DM) is a non-communicable disease that contributes to the cause of death. Based on the analysis of the situation in Kawengen Village, Semarang Regency, there were several problems related to the incidence of DM, including the Non-Communicable Disease Integrated Guidance Post Program (Posbindu PTM), which was not running optimally. Based on these problems, it is necessary to form a movement called the Anti-Diabetes Mellitus Community Alert Movement (SIMANIS). Active case finding and detection of pre-DM cases aim to capture people who already have pre-DM symptoms, but they do not know. Furthermore, if caught, they can be followed up so that they are willing to go to the health service unit before complications occur. The implementation of this community service activity is carried out in four stages, namely the formation of SIMANIS cadres, education on prevention and control of DM to SIMANIS cadres and the community, ToT on how to fill in and use the SIDIA Card (pre-diabetes screening) to SIMANIS cadres, and use of the SIDIA Card for early detection active case finding pre-DM. There was an increase in the pre-post education knowledge score from $7.59+1.5$ to $8.93+0.9$ and an increase in the pre-post education attitude score from $7.96+1.22$ to $9.07+0.78$. SIMANIS through the use of the SIDIA Card can be used to increase public awareness in prevention, early detection, and case finding of DM.
\end{abstract}




\section{PENDAHULUAN}

Diabetes Mellitus (DM) merupakan salah satu penyakit tidak menular yang turut memberi andil dalam penyebab kematian akibat penyakit tidak menular (Peters et al., 2019; Warganegara \& Nur, 2016). Jumlah penderita DM di Indonesia kian meningkat setiap tahun. Indonesia menempati urutan ke-6 dengan populasi penderita DM terbanyak (10,3 juta penduduk) setelah China, India, Amerika Serikat, Brazil, dan Meksiko pada tahun 2017. Jumlah ini diperkirakan meningkat menjadi 16,7 juta penduduk pada tahun 2045. Data lain menunjukkan bahwa proporsi penduduk Indonesia yang tidak menyadari bahwa dirinya DM sebesar 73,7\% dan menempati peringkat ke-4 di dunia, setelah China, India, dan Amerika Serikat (Cho et al., 2018). Selain DM, jumlah orang Indonesia berusia 15 tahun yang mengalami pre-DM mencapai 116 juta jiwa. Hal tersebut menjadi dasar bahwa deteksi dini dan pengobatan segera menjadi poin penting dalam pencegahan DM utamanya pada kelompok umur $\geq 15$ tahun (MarínPeñalver et al., 2016; Badan Penelitian dan Pengembangan Kesehatan Kementerian Kesehatan Republik Indonesia, 2013).

Di Jawa Tengah, DM menempati proporsi terbesar kedua setelah Hipetensi sebesar 19,22\% pada tahun 2017. Dua penyakit tersebut menjadi prioritas utama pengendalian PTM di Jawa Tengah (Dinas Kesehatan Jawa Tengah, 2017). Jika Hipertensi dan Diabetes Melitus tidak dikelola dengan baik maka akan menimbulkan PTM lanjutan seperti Jantung, Stroke, Gagal Ginjal, dan sebagainya (Pugh et al., 2019).

KabupatenSemarang merupakan daerah yang berada di perbatasan sebelah selatan Kota Semarang yang memiliki akses cukup dekat dengan kampus Universitas Negeri Semarang (UNNES). Jarak tempuh dari kampus UNNES menuju Kabupaten Semarang membutuhkan waktu 60 menit melalui perjalanan darat. Wilayah ini terdiri dari daerah urban dan suburban. Di Kabupaten Semarang, jumlah penderita Diabetes Mellitus mengalami peningkatan dari 12.328 kasus pada tahun 2014, 12.448 kasus pada tahun 2015, dan 13.222 kasus pada tahun 2016 (Dinas Kesehatan Kabupaten Semarang, 2016).

Desa Kawengen, Kecamatan Ungaran Timur, Kabupaten Semarang merupakan salah satu daerah suburban yang sangat membutuhkan intervensi kesehatan. Secara umum, pelayanan kesehatan masyarakat diberikan di puskesmas dan bidan desa. Sejak tahun 2016, Desa Kawengen bersama Desa Kalikayen dan Mluweh adalah mitra Prodi Kesehatan Masyarakat, UNNES dalam kegiatan pengajaran, penelitian, dan pengabdian kepada masyarakat. Kesepakatan tersebut tertuang dalam perjanjian kerjasama antara Kecamatan Ungaran Timur dengan Fakultas Ilmu Keolahragaan dimana Prodi Kesehatan Masyarakat, UNNES bernaung.

Berdasarkan analisis situasi di Desa Kawengen, diperoleh 6 permasalahan terkait kejadian DM. Permasalahan pertama adalah Angka prevalensi DM yang tinggi mencapai 6,01\%. Permasalahan kedua adalah DM menjadi penyebab kematian di Desa Kawengen sebesar $11 \%$. Hal tersebut perlu mendapatkan perhatian serius agar dilakukan upaya pencegahan dan pengendalian DM. Permasalahan yang ketiga adalah persentase tingkat konsumsi buah dan sayur pada penduduk Desa Kawengen masih rendah, berturut-turut adalah 43,79\% dan 91,17\%.

Permasalahan yang keempat adalah persentase tingkat aktivitas fisik pada penduduk Desa Kawengen (46,29\%) menduduki peringkat terakhir dibandingkan dengan Kalikayen (47,38\%) dan Mluweh (46,51\%). Konsumsi serat (sayur dan buah) dan aktivitas fisik yang adekuat merupakan faktor pencegah kejadian DM (Sami et al., 2017). Permasalahan yang kelima adalah program Pos 
Pembinaan Terpadu Penyakit Tidak Menular (Posbindu PTM) tidak berjalan optimal, dikarenakan rendahnya pengetahuan kader, minimnya alat deteksi dini, dan terbatasnya media edukasi kesehatan. Permasalahan keenam yang terkait adalah beban kerja bidan yang tinggi dalam pelayanan kesehatan masyarakat, termasuk pemantauan PTM.

Berdasarkan analisis situasi tersebut, maka perlu dibentuk sebuah gerakan sebagai upaya peningkatan kesadaran masyarakat dalam pencegahan, deteksi dini, dan penemuan kasus DM. Gerakan tersebut diberi nama Gerakan Siaga Masyarakat Anti-Diabetes Mellitus (SIMANIS). Deteksi dan penemuan kasus pre-DM secara aktif (active case finding) ini bertujuan untuk menjaring masyarakat yang sudah memiliki gejala preDM, namun dirinya tidak mengetahui. Selanjutnya, apabila terjaring dapat di follow-up agar bersedia memeriksakan diri ke unit pelayanan kesehatan sebelum terjadi penyulit.

Instrumen yang dapat digunakan adalah Kartu SIDIA (Skrining Pre-Diabetes). Kartu SIDIA digambarkan sebagai kartu yang berisikan beberapa parameter yang menunjukkan kondisi pre-DM. Oleh karena itu, pengusul bermaksud untuk mengembangkanSIMANIS melalui Kartu SIDIA sebagai upaya active case finding pre-Diabetes di Desa Kawengen, Kabupaten Semarang. Inti dari solusi yang ditawarkan adalah pembentukan Kader SIMANIS di Desa Kawengen. Kegiatan inti tersebut terdiri dari beberapa kegiatan pendukung, diantaranya adalah edukasi pencegahan dan pengendalian DM melalui 4 pilar pencegahan (edukasi, diet, OAD, dan aktivitas fisik) kepada kader dan masyarakat, ToT cara pengisian dan penggunaan kartu SIDIA kepada kader, dan penggunaan Kartu SIDIA untuk deteksi dini/penemuan kasus (active case finding) pre-Diabetes.

\section{METODOLOGI}

Kegiatan pengabdian masyarakat ini dilaksanakan di Desa Kawengen, Kecamatan Ungaran Timur, Kabupaten Semarang Kegiatan ini berlangsung pada padaSeptember 2019-Februari 2020. Peserta yang terlibat dalam kegiatan ini terdiri atas 30 kader SIMANIS. Metode yang dipilih pada kegiatan pengabdian ini antara lain pembentukan Kader SIMANIS; edukasi pencegahan dan pengendalian DM kepada Kader SIMANIS dan masyarakat; Training of Trainer/ToT cara pengisian dan penggunaan kartu SIDIA (skrining preDiabetes) kepada Kader SIMANIS; dan penggunaan Kartu SIDIA untuk deteksi dini/penemuan kasus (active case finding) pre-DM.

\section{HASIL DAN PEMBAHASAN}

Pembentukan Kader SIMANIS serta Edukasi Pencegahan dan Pengendalian DM

Pembentukan Kader SIMANIS dilakukan bersamaan dengan waktu edukasi Kader SIMANIS sebagaimana ditunjukkan pada Gambar 1. Pembentukan kader perlu dilakukan untuk mendapat dukungan dan pengakuan dari tokoh masyarakat, aparat setempat, dan tenaga kesehatan (Maisya \& Putro, 2011). Selain pembentukan pengurus, kegiatan ini juga menyusun rencana tindak lanjut dari program ini. Dengan adanya tindak lanjut harapannya pelatihan kader ini dapat bermanfaat untuk masyarakat.

Edukasi pencegahan dan pengendalian DM kepada kader dan masyarakat dilakukan dengan tujuan untuk membantu menjalankan program pencegahan dan pemantauan DM di Desa Kawengen. Pembinaan kader berupa pemberian edukasi tentang pencegahan, tanda dan gejala, hingga pengendalian DM dan Pre-DM melalui 4 pilar pencegahan (edukasi, diet, OAD, dan aktivitas fisik). Selain itu juga dilakukan kegiatan 
pelatihan cara mengisi kartu SIDIA sebagai upaya deteksi dini pre-DM.

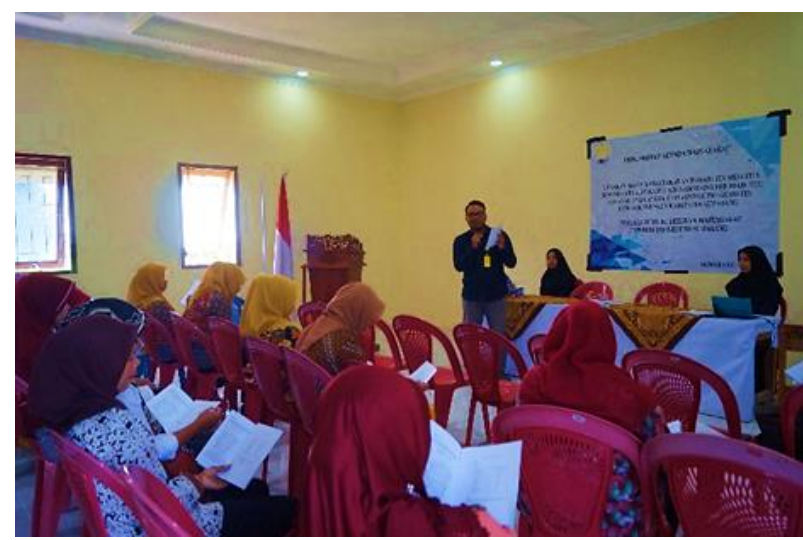

Gambar 1. Kegiatan Edukasi Pencegahan dan Pengendalian DM kepada Kader

Training of Trainer Cara Pengisian dan Penggunaan Kartu SIDIA kepada Kader SIMANIS

Dalam melakukan upaya deteksi dini Diabetes Mellitus, kader dibantu dengan sebuah instrumen yaitu berupa buku panduan Kader SIMANIS dan kartu Skrining preDM (SIDIA) seperti ditunjukkan pada Gambar 2. Buku panduan Kader SIMANIS ini berisi tentang Diabetes Mellitus meliputi definisi, klasifikasi, gejala, faktor risiko, pencegahan dan deteksi dini. Adapun kartu SIDIA digunakan sebagai instrumen untuk skrining pre-DM sehingga masyarakat dapat mengetahui sejak awal jika dirinya berisiko terkena DM atau tidak. Jumlah buku panduan Kader SIMANIS sebanyak 30 eksemplar dan kartu SIDIA sebanyak 50 lembar yang diberikan kepada Kader SIMANIS dan Poskesdes.

Kartu SIDIA merupakan kartu untuk mencatat hasil pengukuran dari 10 item faktor risiko. Sepuluh item tersebut meliputi 1) usia, 2) rasio lingkar pinggang dan pinggul, 3) IMT (berat badan dan tinggi badan), 4) konsumsi gula harian, 5) konsumsi garam harian, 6) riwayat keluarga, 7) tekanan darah, 8) poliuri, 9) polifagia, dan 10) polidipsi. Poin yang sudah didapatkan pada masing-masing kriteria, kemudian dijumlahkan dan dianalisis apakah masuk kedalam pre-DM atau berisiko untuk terkena penyakit Diabetes Mellitus, dengan ketentuan jumlah skor yaitu 10-12 = tidak berisiko, 13-14 = berisiko rendah, 15-16 = berisiko sedang, 17-20 = berisiko tinggi. Praktik pengisian kartu SIDIA ini bertujuan untuk mengetahui ketrampilan Kader SIMANIS dalam upaya deteksi dini pre-DM menggunakan kartu SIDIA.

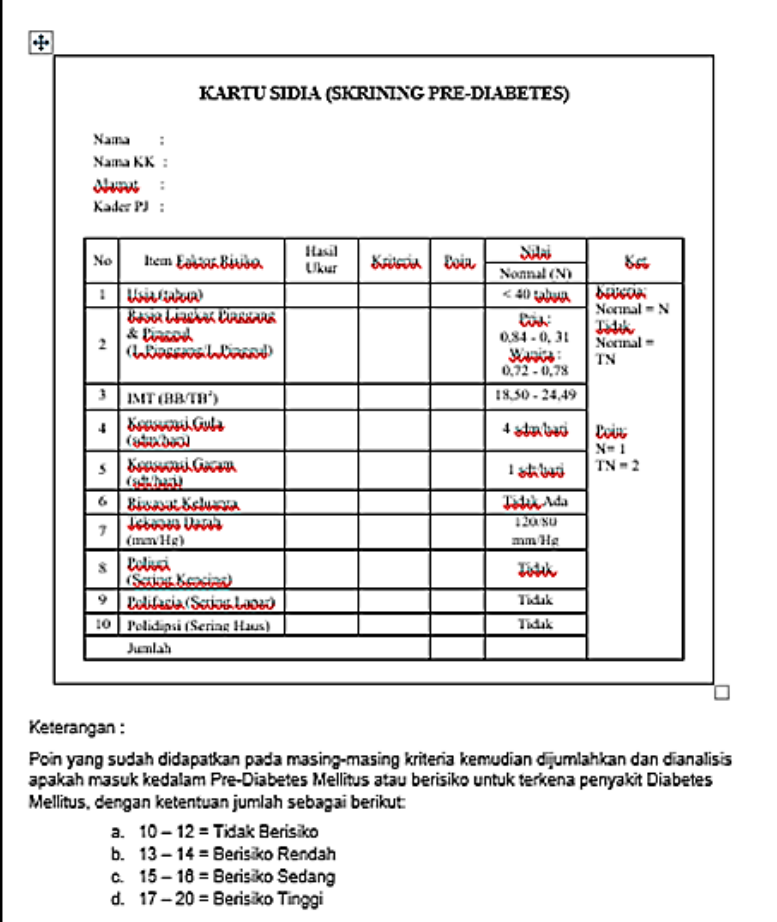

Gambar 2. Kartu SIDIA

Penggunaan Kartu SIDIA untuk Deteksi Dini Pre-DM di Masyarakat

Setelah Kader SIMANIS dibekali dengan pencegahan dan pengendalian DM serta cara pengisian kartu SIDIA untuk deteksi dini pre-DM, kader diminta untuk mempraktikkan pengetahuan dan keterampilan yang didapatnya dengan melakukan deteksi dini langsung di masyarakat. Setiap kader ditugasi untuk melakukan deteksi dini minimal kepada anggota kelurga di sekitar rumah kader.

\section{Hasil Evaluasi}

Untuk mengetahui efektivitas program, maka dilakukan pengukuran skor pre-post pengetahuan dan skor prepost sikap kepada kader SIMANIS dari Kelurahan 
Kawengen. Skor pengetahuan dan sikap Kader SIMANIS sebelum dan sesudah edukasi pencegahan dan pengendalian DM menunjukkan adanya perbedaan ( $p<0,01$ ). Tabel I menunjukkan hasil perbedaan pada aspek pengetahuan dan sikap pada Kader SIMANIS sebelum dan sesudah diberikan edukasi. Skor pengetahuan sebelum edukasi sebesar 7,59 $\pm 1,5$ meningkat menjadi 8,93 $\pm 0,9$ setelah edukasi. Adapun skor sikap sebelum edukasi sebesar 7,96 $\pm 1,22$ meningkat menjadi 9,07士0,78 setelah edukasi.

Tabel I. Gambaran Pengetahuan dan Sikap Kader SIMANIS Sebelum dan Sesudah diberikan Edukasi

\begin{tabular}{llllcc}
\hline \multicolumn{1}{c}{ Variabel } & Test & Min & Max & $\begin{array}{c}\text { Rerata } \pm \\
\text { SD }\end{array}$ & p \\
\hline Pengetahuan & Pre & 5 & 10 & $7,59 \pm 1,50$ & $<0,01$ \\
& Post & 7 & 10 & $8,93 \pm 0,99$ & \\
Sikap & Pre & 6 & 10 & $7,96 \pm 1,22$ & $<0,01$ \\
& Post & 8 & 10 & $9,07 \pm 0,78$ & \\
\hline
\end{tabular}

\section{KESIMPULAN}

Berdasarkan hasil pelaksanakan kegiatan pengabdian kepada masyarakat Gerakan SIMANIS melalui Kartu SIDIA, maka dapat disimpulkan bahwa telah dilaksanakan kegiatan pengabdian kepada masyarakat untuk pembentukan Kader SIMANIS, edukasi pencegahan dan pengendalian DM melalui 4 pilar pencegahan (edukasi, diet, OAD, dan aktivitas fisik) kepada Kader SIMANIS, ToT cara pengisian dan penggunaan kartu SIDIA kepada Kader SIMANIS, dan penggunaan KartuSIDIA untuk deteksi dini/penemuan kasus (active case finding) pre-DM di masyarakat. Saran yang diberikan kepada Puskesmas Kalongan dan Pemerintah Desa Kawengen diantaranya adalah diperlukan pendampingan kader berkelanjutan oleh Puskesmas Kalongan atau Pemerintah Desa Kawengen agar program ini dapat berjalan dengan optimal, refreshing materi perlu dilakukan secara berkala oleh Puskesmas Kalongan sehingga update ilmu dapat terus diberikan kepada kader, pemberian rewards oleh Puskesmas Kalongan kepada kader yang melakukan deteksi dini pre-DM atau PTM lainnya di wilayahnya secara rutin, serta diperlukan pengembangan Kader SIMANIS di desa lain oleh Puskesmas Kalongan yang bekerja sama dengan pemerintah desa.

\section{UCAPAN TERIMA KASIH}

Ucapan terima kasih disampaikan kepada Fakultas Ilmu Keolahragaan UNNES atas hibah pengabdian kepada masyarakat, bidan, kader SIMANIS, dan seluruh warga Desa Kalongan.

\section{REFERENSI}

Badan Penelitian dan Pengembangan Kesehatan Kementerian Kesehatan Republik Indonesia. 2013. Riset Kesehatan Dasar 2013: Laporan Nasional 2013. Jakarta: Badan Penelitian dan Pengembangan Kesehatan Kementerian Kesehatan Republik Indonesia

Cho, N.H., Shaw, J.E., Karuranga, S., Huang, Y., Fernandes, J.D.R., Ohlrogge, A.W., Malanda, B. 2018. IDF Diabetes Atlas: Global estimates of diabetes prevalence for 2017 and projections for 2045. Diabetes Research and Clinical Practice. 138:271-281.

https://doi.org/10.1016/j.diabres.2018.02.023

Dinas Kesehatan Jawa Tengah. 2017. Profil Kesehatan Jawa Tengah Tahun 2017. Semarang: Dinas Kesehatan Jawa Tengah

Dinas Kesehatan Kabupaten Semarang. 2016. Profil Kesehatan Kabupaten Semarang Tahun 2016. Semarang: Dinas Kesehatan Kabupaten Semarang

Maisya, I.B., Putro, G. 2011. Peran Kader Dan Klian Adat Dalam Upaya Meningkatkan Kemandirian Posyandu Di Provinsi Bali (Studi Kasus Di Kabupaten Badung, Gianyar, Klungkung Dan Tabanan). Buletin Penelitian Sistem Kesehatan. 14(1):40-48.

Marín-Peñalver, J.J., Martín-Timón, I., SevillanoCollantes, C., Cañizo-Gómez, F.J. 2016. Update on the treatment of type 2 diabetes mellitus. World Journal of Diabetes. 7(17):354-395. https://dx.doi.org/10.4239/wjd.v7.i17.354 
Peters, R., Ee, N., Peters, J., Beckett, N., Booth, A., Rockwood, K., Anstey, K.J. 2019. Common risk factors for major noncommunicable disease, a systematic overview of reviews and commentary: the implied potential for targeted risk reduction. Therapeutic Advances in Chronic Disease. 10:2040622319880392. https://dx.doi.org/10.1177/204062231988039 2

Pugh, D., Gllacher, P.J., Dhaun, N. 2019. Management of Hypertension in Chronic Kidney Disease. Drugs. $\quad$ 79(4):365-379. https://dx.doi.org/10.1007/s40265-019-10641

Sami, W., Ansari, T., Butt, N.S., Ab Hamid, M.R. 2017. Effect of diet on type 2 diabetes mellitus: A review. International Journal of Health Sciences. 11(2):65-71.

Warganegara, E., Nur, N.N. 2016. Faktor Risiko Perilaku Penyakit Tidak Menular. Majority (Medical Journal of Lampung University). 5(2):88-94. 